\title{
Helper Component-Transcomplementation in the Vector Transmission of Plant Viruses
}

\author{
Rémy Froissart, Yannis Michalakis, and Stéphane Blanc
}

First and third authors: Station de Pathologie Comparée, Unité Mixte de Recherche 5087 INRA/CNRS/Université Montpellier II, 30380 Saint-Christol-lez-Alès France; and second author: Centre d'Étude sur le Polymorphisme des Micro-organismes, UMR 9926, IRD, 911 avenue d'Agropolis, 34032 Montpellier Cedex 01 France. Accepted for publication 8 March 2002.

\begin{abstract}
Froissart, R., Michalakis, Y., and Blanc, S. 2002. Helper componenttranscomplementation in the vector transmission of plant viruses. Phytopathology 92:576-579.

Plant viruses are most frequently transmitted from one host plant to another by vectors. In noncirculative vector transmission, the virus does not process through a cycle within the vector body. Instead, upon acquisition by the vector, viruses are retained in the mouth parts or the anterior gut; from there, they will be subsequently released in a new host plant. Two molecular strategies have been described for the virus-vector interaction. In the capsid strategy, the virus coat interacts directly with binding sites in the vector mouth parts, whereas an additional nonstructural protein, designated helper component $(\mathrm{HC})$, is required in the

helper strategy. The $\mathrm{HC}$ and virus particles can be acquired sequentially, and this property introduces the possibility that an HC acquired first by the vector assists the transmission of virus particles located in the same cell, in other cells, or even in other host plants probed by the vector. Such a phenomenon is here called HC-transcomplementation. Surprisingly, the existing definition of $\mathrm{HC}$ does not explicitly include the concept of HCtranscomplementation, and it is generally omitted in the literature in any consideration of the virus biology other than the molecular interaction with the vector. Here we propose an extended definition of $\mathrm{HC}$ and emphasize the concept of HC-transcomplementation that distinguishes the helper strategy from any other type of vector transmission and may have consequences at the level of the virus population genetics and evolution.
\end{abstract}

Host-to-host transmission is a key step in the biological cycle of parasites. Most plant viruses overcome this problem by using a plant-feeding organism, the vector, as a mean of transportation from one host to another. Vectors are taxonomically very diverse and can be found among arthropodes, fungi, and nematodes. They are most frequently insects of the order Homoptera, especially aphids. Vector transmission consists of three steps: acquisition, retention, and inoculation of the virus by the vector. The mechanisms of the virus-vector interaction complying with this basic pattern, however, can vary tremendously depending on the virus group (comprehensive reviews: 6,15).

In noncirculative transmission (recent review: 18), the virus does not infect the vector, nor does it cross vector membranes and enter into the hemocoel. Instead, the virus specifically associates with a putative receptor located either on the cuticle lining of the maxillary food and salivary canal in the vector mouth parts or on that lining the anterior alimentary tract. The virus is subsequently released and inoculated upon salivation or regurgitation. Noncirculative plant viruses have evolved two distinct molecular strategies regulating their interaction with vectors (17): the capsid strategy in which the virus coat (coat protein $[\mathrm{CP}]$ ) interacts directly with the vector, and the helper strategy in which at least one nonstructural viral gene product, the helper component (HC), is required for successful transmission (Fig. 1).

HCs were first described in the 1970s by Kassanis and Govier $(5,10,11)$, who noted that aphid transmission of Potato virus $C$ (PVC) was possible only when plants were also infected by Potato virus $Y$ (PVY). Furthermore, transmission of PVC from singly infected plants occurred when aphids were previously fed

Corresponding author: S. Blanc; E-mail address: blanc@ensam.inra.fr

Publication no. P-2002-0416-01V

(C) 2002 The American Phytopathological Society on a plant infected by PVY. It was concluded that a factor, produced in plants upon PVY infection, subsequently assisted the transmission of PVC by aphids. Additional work by Kassanis and Govier $(10,11)$ demonstrated that this factor was not the PVY virus particle itself, but rather a nonstructural protein that was designated $\mathrm{HC}$ and later demonstrated to be virus-encoded (21).

The best studied examples illustrating the helper strategy are found in the genera Potyvirus (19) and Caulimovirus (3). A model termed the bridge hypothesis (17) is commonly accepted to explain the mode of action of $\mathrm{HC}$, and describes these nonstructural proteins as molecules capable of engaging two types of interactions: one with the virus $\mathrm{CP}$ and the other with a putative receptor in the vector's mouth parts. Thus, a reversible "molecular bridge" allowing virus retention in the vector would be created (Fig. 1). The bridge hypothesis implies that loss of transmissibility can result either from mutations in the $\mathrm{HC}$ that render it nonfunctional, or from defects in the $\mathrm{CP}$ abolishing the $\mathrm{HC}-\mathrm{CP}$ interaction.

If transcomplementation is defined as an assistance between viral genomes for a given function, then the potential for transcomplementation of vector transmission is clearly different in the capsid and helper strategies. In both, transcapsidation allows the vector transmission of a genome of a nontransmissible isolate (due to a defect in the $\mathrm{CP}$ ) encapsidated in the $\mathrm{CP}$ originating from a transmissible isolate. An additional type of transcomplementation exists, however, in the helper strategy. Indeed, because the acquisition by the vector of $\mathrm{HC}$ and virions can be sequential, provided $\mathrm{HC}$ is acquired first, it is possible for a genome $\mathrm{X}$ to assist the transmission of a genome Y, through the action of the HC (Fig. 1). In this case, the genome $\mathrm{X}$ would encode for a functional $\mathrm{HC}$, whereas the genome $\mathrm{Y}$ would not necessarily do so. Definitive evidence for such HC-transcomplementation has been frequently reported for potyviruses, caulimoviruses, waïkaviruses, and sequiviruses (18). Moreover, it may also occur in tobraviruses, because 
nonstructural viral proteins are suspected to play a crucial role in nematode transmission (14).

Experimental sequential feeding of aphids with the $\mathrm{HC}$ and viruses has been used for decades as a mean to study the molecular mechanisms of virus-vector interaction. Nevertheless, in planta or natural HC-transcomplementation is detected only when it occurs between different virus species or strains that can be readily distinguished. Although the intrapopulation HC-transcomplementation cannot be experimentally quantified, Pirone and Blanc (17) suggested its possible impact on the evolution and epidemiology of the corresponding viruses. Interestingly, Drucker et al. (4) recently demonstrated that the transmissible complex of Cauliflower mosaic virus (CaMV) does not primarily form in infected plant cells but in the insect vector, after sequential acquisition of $\mathrm{HC}$ and virus particles. Drucker et al. (4) concluded that this phenomenon likely results in the HC-transcomplementation being predominant upon natural CaMV vector transmission.

In recent reviews it appears that the consensual definition of $\mathrm{HC}$ corresponds to that given by Pirone and Blanc (17) as virusencoded factors that are not constituents of the virion and are required for vector transmission. As an extended definition, we will consider an $\mathrm{HC}$ as any factor complying with all of the following criteria: (i) an $\mathrm{HC}$ is virus-encoded, (ii) an $\mathrm{HC}$ is one or a complex of several nonstructural molecules (i.e., which can be eliminated upon purification of virions), (iii) an $\mathrm{HC}$ is necessary for the success of vector transmission, and (iv) the $\mathrm{HC}$ and the virion can be acquired sequentially by the vector.

Concepts newly included in this definition are in criteria two and four. It is important to acknowledge that an $\mathrm{HC}$ can be a complex of different molecules, because in this case, several levels of transcomplementation potentially exist. The requirement of two nonstructural viral proteins has been suggested for nematode transmission of tobraviruses (14) and recently demonstrated for the aphid transmission of caulimoviruses (13).

The possibility that the $\mathrm{HC}$ and the virion can be sequentially acquired is the central aspect of this extended definition. Indeed, sequential acquisition may occur upon vector probing in one single cell, in several different cells, or even in different hosts. Thus, when the transmissible complex is formed in the vector and not in plant cells, sequential acquisition allows for transcomplementation at a level significantly different from that allowed through transcapsidation. Though sequential acquisition has never been explicitly included in the definition of $\mathrm{HC}$, this should be considered as its main biological feature. For example, Hull (9) qualified the readthrough (RT) domain of the $\mathrm{CP}$ of luteoviruses as an integrated helper because it plays a role in virus-vector interaction. This RT domain is covalently linked to some CP molecules, so its acquisition and that of the virion cannot be sequential. Hence, the RT domain of the $\mathrm{CP}$ in members of the family Luteoviridae does not comply with criterion four because it does not allow HC-transcomplementation. In the case of CaMV, where at least two viral nonstructural factors (P2 and P3) are mandatory for successful vector transmission $(12,13)$, Drucker et al. (4) recently demonstrated that only P2 can be acquired independently from the virions. P3-virion complexes must be preformed prior to acquisition by aphids to allow for successful transmission. Therefore, P3 does not comply with criterion four of our definition and, thus, only P2 is the HC of CaMV.

Nontransmissible variants with a mutation rendering the $\mathrm{HC}$ nonfunctional are frequently described in caulimoviruses and potyviruses. At least three naturally occurring $\mathrm{HC}$-deficient isolates of CaMV have been described (the origin of these isolates is described in literature citation 20). One has a deletion encompassing the entire coding sequence of the $\mathrm{HC}(8)$, whereas the other two harbor a point mutation in the $\mathrm{HC}$ that is responsible for lack of aphid transmission (23). Moreover, Al-Kaff and Covey (1) demonstrated that such nontransmissible variants appear frequently during a single CaMV infection cycle initiated by a transmissible inoculum. In potyviruses, numerous similar nontransmissible variants have also been described (19). They produce a nonfunctional $\mathrm{HC}$ due to point mutations affecting the binding between either HC and aphids (2) or HC and virions (16). That HC-transcomplementation could participate in the frequent natural occurrence of HC-defective variants within a virus species is suggested

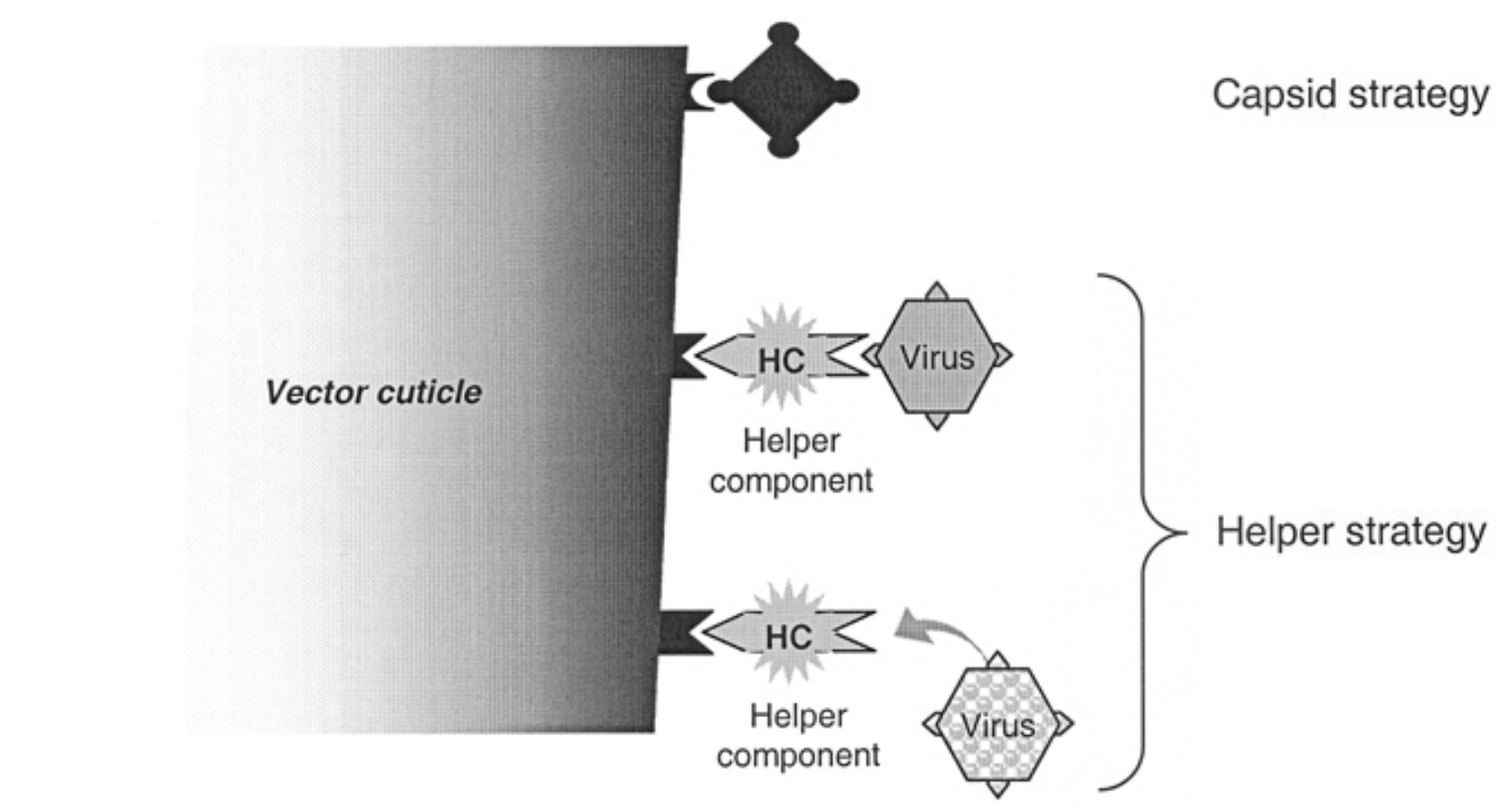

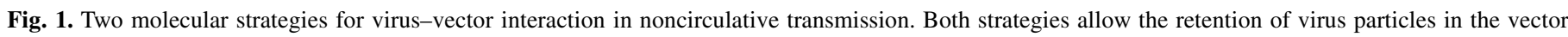

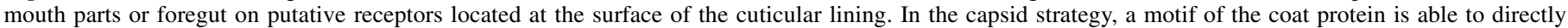

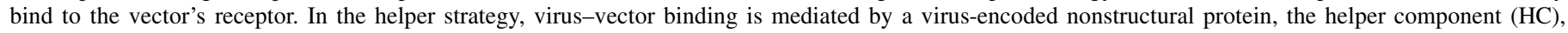

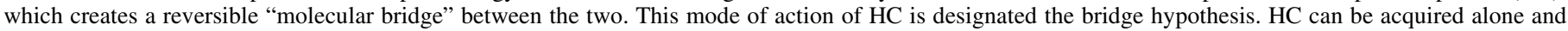
thereby allow HC-transcomplementation as symbolized by the arrow and a different shading for the virus particle subsequently acquired. 


\begin{tabular}{|c|c|c|c|c|c|}
\hline \multirow[b]{2}{*}{ Virus genera $^{\mathrm{a}}$} & \multicolumn{2}{|c|}{ Helper strategy } & \multicolumn{2}{|c|}{ Capsid strategy } & \multirow[b]{2}{*}{ Genome } \\
\hline & Use of HC hypothesized ${ }^{b}$ & Use of $\mathrm{HC}$ demonstrated ${ }^{\mathrm{c}}$ & No use of HC hypothesized ${ }^{b}$ & No use of $\mathrm{HC}$ demonstrated ${ }^{\mathrm{c}}$ & \\
\hline Alfamovirus & $\ldots$ & $\ldots$ & $\ldots$ & + & $\ldots$ \\
\hline Badnavirus (RTBV)d & $\ldots$ & + & $\ldots$ & $\ldots$ & DNA \\
\hline Carlavirus & $\ldots$ & $\ldots$ & + & $\ldots$ & $\ldots$ \\
\hline Caulimovirus & $\ldots$ & + & $\ldots$ & $\ldots$ & DNA \\
\hline Closterovirus & + & $\ldots$ & $\ldots$ & $\ldots$ & $\ldots$ \\
\hline Cucumovirus & $\ldots$ & $\ldots$ & $\ldots$ & + & $\ldots$ \\
\hline Potyvirus & $\ldots$ & + & $\ldots$ & $\ldots$ & $\ldots$ \\
\hline Sequivirus & $\ldots$ & + & $\ldots$ & $\ldots$ & $\ldots$ \\
\hline Waïkavirus & $\ldots$ & + & $\ldots$ & $\ldots$ & $\ldots$ \\
\hline Subtotal & 2 & 4 & 1 & 2 & $\ldots$ \\
\hline Total & \multicolumn{2}{|c|}{6} & \multicolumn{2}{|c|}{3} & \\
\hline
\end{tabular}

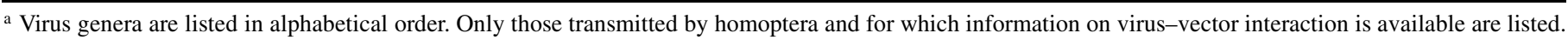
All listed viruses have an RNA genome unless otherwise mentioned.

${ }^{\mathrm{b}}$ Only preliminary data or indirect evidence reported.

c Direct experimental evidence reported on use of helper component (HC).

${ }^{\mathrm{d}}$ Rice tungro bacilliform virus (RTBV) is the only well-documented case in this genus.

by following examples in which a virus species is intrinsically HC-deficient and is transmitted exclusively in the presence of an HC encoded by a phylogenetically distant coinfecting virus. Though the $\mathrm{HC}$-virion interactions are usually specific of a virus genus, intergeneric HC-transcomplementation has been demonstrated in some instances. The best documented cases are those of Potato aucuba virus (PAMV, a member of the genus Potexvirus) and Rice tungro bacilliform virus (RTBV, a member of the genus Badnavirus), for which vector transmission depends on an $\mathrm{HC}$ produced by a coinfecting potyvirus and waïkavirus, respectively $(7,10)$. It is likely that PAMV and RTBV are not deletion mutants derived from HC-producing ancestors, but rather have been able to take advantage of exogenous $\mathrm{HC}$ by appropriate adaptation of their CP. Indeed, both belong to taxonomic groups in which the other members are not transmitted through the helper strategy (22). These striking examples further illustrate the fact that a significant proportion of a virus population can be reliably transmitted through HC-transcomplementation. More specifically, they unequivocally demonstrate that obligate HC-transcomplementation for host-to-host transmission can even be a stable strategy allowing the evolutionary maintenance of a virus.

Accurate information on the distribution of the helper strategy across viral species should provide us with useful insights into at least two important questions: first, whether this strategy evolved several times independently, and second, whether it is a derived or an ancestral trait in the clades in which it has evolved. Unfortunately, there are few virus species in which the existence or absence of HC has been fully documented (Table 1). Despite the fragmentary nature of the available data, however, some preliminary inferences are possible.

The helper strategy has been reported both in RNA (genera Potyvirus and Waïkavirus) and DNA viruses (genus Caulimovirus belonging to the pararetrovirus group), which have totally different genome organizations and mechanisms of gene expression (Table 1). No sequence or protein structure similarity could be found between the $\mathrm{HC}$ of potyviruses and caulimoviruses ( $\mathrm{S}$. Blanc, unpublished data), suggesting that the helper strategy must have evolved at least twice independently. More detailed phylogenetic studies on appropriate genes are needed before we can say whether the helper strategy evolved once within each category or many times.

Similar phylogenetic studies should also reveal whether the helper strategy is an ancestral or a derived trait of the clades that have adopted it. Moreover, such studies could provide evidence on whether the use of a helper strategy is an obligate step toward the acquisition of the noncirculatively vector-transmitted way of life in plant viruses, a constraint which was perhaps relaxed later on during evolution in certain cases. Helper strategies may also have led to diversification of the clades that adopted them relative to sister clades which did not. Indeed, the available evidence indicates that the helper strategy is the most common among noncirculative viruses for which enough information about virusvector interaction is available (Table 1). It is evident, however, that this conclusion needs firmer grounds (i.e., more cases where the presence or absence of $\mathrm{HC}$ is adequately documented) and a phylogenetic context before it can be definitively accepted.

Pirone and Blanc (17) have speculated on the effect of HCtranscomplementation on the biology and genetics of virus populations and have suggested that several viruses may have independently converged to the helper strategy. We currently lack an appropriate phylogenetic context that would allow us to interpret and evaluate the role of the evolution of this strategy for the evolution of the noncirculative vector-transmission trait. It is important to note that information on animal viruses with the same trait is totally lacking and badly needed. Future studies may also reveal whether the helper strategy incurs fitness costs on its carriers, as the natural occurrence of spontaneous variants or isolates without functional helpers would suggest. Such studies should also elucidate the epidemiological, genetic, and evolutionary consequences of HC-transcomplementation as well as provide insight into why some viruses, e.g., Cucumovirus, apparently can persist without it.

\section{LITERATURE CITED}

1. Al-Kaff, N., and Covey, S. N. 1994. Variation in biological properties of cauliflower mosaic virus clones. J. Gen. Virol. 75:3137-3145.

2. Blanc, S., Ammar, E. D., Garcia-Lampasona, S., Dolja, V. V., Llave, C., Baker, J., and Pirone, T. P. 1998. Mutations in the potyvirus helper component protein: Effects on interactions with virions and aphid stylets. J. Gen. Virol. 79:3119-3122.

3. Blanc, S., Hébrard, E., Drucker, M., and Froissart, R. 2001. Molecular basis of vector transmission: Caulimoviruses. Pages 143-166 in: VirusInsect-Plant Interactions. K. Harris, O. P. Smith, and J. E. Duffus, eds. Academic Press, San Diego.

4. Drucker, M., Froissart, R., Hebrard, E., Uzest, M., Ravallec, M., Esperandieu, P., Mani, J. C., Pugniere, M., Roquet, F., Fereres, A., and Blanc, S. 2002. Intracellular distribution of viral gene products regulates a complex mechanism of cauliflower mosaic virus acquisition by its aphid vector. Proc. Natl. Acad. Sci. USA 99:2422-2427.

5. Govier, D. A., and Kassanis, B. 1974. A virus induced component of plant sap needed when aphids acquire potato virus y from purified preparations. Virology 61:420-426.

6. Gray, S. M., and Banerjee, N. 1999. Mechanisms of arthropod transmission of plant and animal viruses. Microbiol. Mol. Biol. Rev. 63:128-148.

7. Hibino, H., and Cabauatan, P. Q. 1987. Infectivity neutralization of rice tungro-associated viruses acquired by vector leafhoppers. Phytopathol- 
ogy $77: 473-476$

8. Howarth, A. J., Gardner, R. C., Messing, J., and Shepherd, R. J. 1981. Nucleotide sequence of naturally occurring deletion mutants of cauliflower mosaic virus. Virology 112:678-685.

9. Hull, R. 1994. Molecular biology of plant virus-vector interactions. Pages 361-386 in: Advances in Disease Vector Research, Vol. 10. Springer-Verlag, New York.

10. Kassanis, B., and Govier, D. A. 1971. The role of the helper virus in aphid transmission of potato aucuba mosaic virus and potato virus c. J. Gen. Virol. 13:221-228.

11. Kassanis, B., and Govier, D. A. 1971. New evidence on the mechanism of transmission of potato $\mathrm{c}$ and potato aucuba mosaic viruses. J. Gen. Virol. 10:99-101.

12. Leh, V., Jacquot, E., Geldreich, A., Haas, M., Blanc, S., Keller, M., and Yot, P. 2001. Interaction between cauliflower mosaic virus orfiii product and the coat protein is required for transmission of the virus by aphids. J. Virol. 75:100-106.

13. Leh, V., Jacquot, E., Geldreich, A., Hermann, T., Leclerc, D., Cerrutti, M., Yot, P., Keller, M., and Blanc, S. 1999. Aphid transmission of cauliflower mosaic virus requires the viral piii protein. EMBO J. 18:70777085 .

14. McFarlane, S. A. 1999. Molecular biology of the tobraviruses. J. Gen. Virol. 80:2799-2807.

15. Nault, L. R. 1997. Arthropod transmission of plant viruses: A new synthesis. Ann. Entomol. Soc. Am. 90:521-541.

16. Peng, Y. H., Kadoury, D., Gal-on, A., Huet, H., Wang, Y., and Raccah, B.
1998. Mutations in the hc-pro gene of zucchini yellow mosaic potyvirus: Effects on aphid transmission and binding to purified virions. J. Gen. Virol. 79:897-904.

17. Pirone, T., and Blanc, S. 1996. Helper-dependent vector transmission of plant viruses. Annu. Rev. Phytopathol. 34:227-247.

18. Pirone, T. P., and Perry, K. L. 2002. Aphids-non-persistent transmission. Advances in Botanical Research, Vol. 36. R. T. Plumb, ed. Academic Press, London.

19. Raccah, B., Huet, H., and Blanc, S. 2001. Potyviruses. Pages 181-206 in: Virus-Insect-Plant Interactions. K. Harris, J. E. Duffus, and O. P. Smith, eds. Academic Press, San Diego.

20. Shalla, T. A., Sheperd, R. J., and Petersen, L. J. 1980. Comparative cytology of nine isolates of cauliflower mosaic virus. Virology 102:381388 .

21. Thornbury, D. W., and Pirone, T. P. 1983. Helper components of two potyviruses are serologically distinct. Virology 125:487-490.

22. Van Regenmortel, M. H. V., Fauquet, C. M., Bishop, D. H. L., Carstens, E. B., Estes, M. K., Lemon, S. M., Maniloff, J., Mayo, M. A., Mcgeoch, D. J., Pringle, C. R., and Wickner, R. B. 2000. Virus Taxonomy: The Classification and Nomenclature of Viruses. The Seventh Report of the International Committee on Taxonomy of Viruses. Academic Press, San Diego.

23. Woolston, C. J., Czaplewski, L. G., Markham, P. G., Goad, A. S., Hull, R., and Davies, J. W. 1987. Location and sequence of a region of cauliflower mosaic virus gene ii responsible for aphid transmissibility. Virology 160:246-251. 